\title{
Implementation research training for learners in low- and middle-income countries: Evaluating behavior change after participating in a massive online open course
}

\author{
Pascal Launois \\ WHO \\ Dermot Maher \\ WHO \\ Edith Certain \\ WHO
}

Bella Ross ( $\nabla$ bella.ross@monash.edu )

Monash University - Caulfield Campus https://orcid.org/0000-0002-1686-8264

Michael J. Penkunas

UNU - IIGH: United Nations University International Institute for Global Health

\section{Research}

Keywords: Training, Massive online open course, Low- and middle-income countries, Kirkpatrick Model

Posted Date: November 18th, 2020

DOI: https://doi.org/10.21203/rs.3.rs-105115/v1

License: (c) (1) This work is licensed under a Creative Commons Attribution 4.0 International License.

Read Full License 


\section{Abstract \\ Background}

Implementation research (IR) can play a critical role in the delivery of disease control interventions, particularly in low- and middle-income countries (LMICs). The growing demand for IR training has led to the development of a range of training programs and university courses, the majority of which can not be accessed by learners in LMICs. This article reports on the evaluation of a massive open online course (MOOC) developed by the Special Programme for Research and Training in Tropical Diseases hosted by the World Health Organization on the topic of IR with a focus on infectious diseases of poverty. This study followed Kirkpatrick's Model to evaluate training programs with a specific focus on post-training changes in behavior.

\section{Methods}

MOOC participants were invited to take part in an anonymous online survey examining their IR knowledge and how they applied it in their professional practice approximately 1-1.5 years after completing the MOOC. The survey contained 43 open-ended, multiple choice and Likert-type questions. Descriptive statistics were calculated for the quantitative data and responses to the open-ended questions were thematically coded.

\section{Results}

A total of $748 \mathrm{MOOC}$ participants responded to the survey. The demographic profile of the survey respondents aligned with that of the $\mathrm{MOOC}$ participants, with nearly $70 \%$ of respondents originating from Africa. Responses to the quantitative and open-ended survey questions revealed that respondents' IR knowledge had improved to a large extent as a result of the $\mathrm{MOOC}$, and that they used the knowledge and skills gained in their professional lives frequently. Respondents most often cited changes in their conceptual understanding of IR and understanding of the research process as substantial areas of change influenced by participating in the MOOC.

\section{Conclusions}

These findings indicate that the MOOC was successful in targeting learners from LMICs, in strengthening their IR knowledge and in contributing to their ability to apply it in their professional practice. The utility of MOOCs for providing IR training to learners in LMICs, where implementation challenges are encountered often, makes this platform an ideal standalone learning tool or one that could be combined with other training formats. 


\section{Contributions To The Literature}

- Implementation research plays a crucial role in disease control interventions.

- Efficacious interventions are particularly needed in low- and middle-income countries in relation to infectious diseases of poverty.

- Knowledge and training in implementation research is limited in low- and middle-income countries.

- Online training, such as a MOOC, provides a proven way to educate a broad section of learners in low- and middle-income countries about implementation research.

\section{Background}

Health systems have an ever growing suite of evidence-based interventions at their disposal - vaccines, pharmaceuticals, diagnostic technologies - yet these interventions often do not translate into real world impact when introduced at scale. ${ }^{1}$ The need to address implementation bottlenecks for efficacious health interventions is often greatest in low- and middle-income countries (LMICs), where health systems are underdeveloped and do not have established mechanisms to effectively collect and use locally generated information. ${ }^{2}$ Building research capacities to identify and enact strategies for overcoming implementation challenges is increasingly important as countries strive for universal health coverage while combating the burden of infectious and non-communicable diseases at varying levels of intensity. Researchers in LMICs are in the best position to produce locally generated evidence for priority-setting to ensure interventions remain relevant, sustainable, and are implemented optimally when scaled.

While implementation research (IR) can play a critical role in the delivery of disease control interventions, it is an area that is only recently gaining attention and support. ${ }^{3}$ The increasing interest in IR and growing demand for IR training has led to the development of a range of training programs and university courses, ${ }^{4-6}$ which were not widely taught until recently. ${ }^{5}$ Yet, the majority of these formal courses remain out of reach for researchers in LMICs. In order to disseminate IR concepts widely and train public health researchers, practitioners, and policy makers in LMICs, the Special Programme for Research and Training in Tropical Diseases (TDR) hosted by the World Health Organization developed a massive open online course (MOOC), which was piloted with success in 2017 and rolled out to wider audiences in $2018 .{ }^{7}$

\section{The TDR Implementation Research MOOC}

MOOCs are gaining popularity as professional development and credentialing tools ${ }^{8}$ and can increase professional knowledge of a new topic ${ }^{9}$ and develop new skills. ${ }^{10}$ MOOCs historically display low retention rates in high-income countries ${ }^{11-13}$ though completion rates of professional development MOOCs have been found to be higher in LMICs. ${ }^{14-16}$ Beyond learner retention in MOOCs, whether or not participants apply their learnings to their professional lives remains a substantial limitation. ${ }^{17-18}$ 
The IR MOOC examined here was developed by TDR through a series of consultations and engagements with recognized experts in IR. The focus for the MOOC is on applying IR concepts to increase the effectiveness of interventions for combating infectious diseases of poverty. The IR MOOC was developed to address the relative lack of education and training opportunities in IR in LMICs. The five module MOOC is delivered over six weeks and illustrates through a series of videos IR concepts with worked case studies that are introduced, presented, and interpreted by experienced public health experts. Videos in the MOOC range from approximately 4 minutes to approximately 25 minutes in length and are divided into the five following modules: 1) What is Implementation Research, 2) Needs Assessment for Implementation Research, 3) Designing Implementation Research, 4) Implementation Research Outcomes, 5) Implementation Research in Practice. Discussion forums further exploring the concepts presented in the video presentations are facilitated by TDR trainers and encourage interaction among students. The $\mathrm{MOOC}$ targets researchers and practitioners and intends to build foundational knowledge of IR methods, purpose, and approaches. ${ }^{19-20}$

The IR MOOC is currently offered in English, French, and Spanish with, Russian and Chinese and Arabic versions to be offered in 2020 and early 2021 respectively. Further refinements of the MOOC are currently under development including the development of additional, specialized modules on in-demand topics such as qualitative methods, community engagement, and integrating gender and intersectionality into IR studies. In addition, although the MOOC was developed with a focus on infectious diseases of poverty, it has been adapted for strengthening IR capacity around non-communicable diseases. ${ }^{21}$

\section{Evaluation using the Kirkpatrick Model}

Evaluation is critical for assessing the effectiveness and value of a MOOC. ${ }^{22}$ The Kirkpatrick Model is widely used to evaluate training programs and has been used previously to evaluate MOOCs for learners in high-income settings. ${ }^{23-27}$ The model comprises four levels and examines: 1) reaction, 2) learning, 3) behaviour and 4) results. The Kirkpatrick model provides a framework for both short- and long-term evaluations, ${ }^{28}$ with short-term evaluations typically focus on learners' more immediate reactions to the training and their learning. Long-term evaluations explore whether and how learners have used the training to modify behaviour and any concrete results several months to years after the training takes place.

Evaluations of the immediate reaction and learning of the IR MOOC participants showed significant improvement toward strong and very strong IR knowledge. ${ }^{29}$ Approximately three quarters $(72.3 \%)$ of surveyed participants indicated that $\mathrm{MOOC}$ met their expectations and $80.9 \%$ indicated substantial improvement in IR knowledge. ${ }^{29}$

The current paper presents an evaluation of behaviour. Behaviour refers to how the new knowledge, skills and attitudes are applied in practice. For this study, we examine if and how participants' applied the concepts presented in the IR MOOC in their professional roles and responsibilities. 


\section{Methods}

The analysis of participants' behaviour is based on online, anonymous survey data collected between November 2019 and February 2020. The survey data includes both quantitative and qualitative data, where the qualitative data assisted in contextualizing the quantitative findings and ensured the comprehensiveness of the results. The two main areas under examination here are knowledge and changes in professional behaviour. The quantitative and qualitative data is integrated in the presentation of findings according to these two areas; the overall areas of change are presented first using quantitative data followed by the qualitative data that explores in further detail the themes and nuances of responses.

The survey consisted of 43 questions, which included open-end, multiple choice and Likert-type questions. Questions centred on four areas: 1) participant demographics, 2) satisfaction with the MOOC, 3) change in professional behaviour following the MOOC, and 4) results following the MOOC that affected either the participant's professional work or their organisation.

Ten previous IR MOOC participants were invited to pilot the survey on 23 November 2019. Of these, four responded to the invitation within the requested three-day period. The survey was modified slightly following analysis of the pilot responses. The link to the revised survey was emailed to all IR MOOC participants from the May and October cohorts in November 2019 and three reminder emails were sent during the next 10 weeks. In total, 748 responses were recorded between November 2019 and February 2020 , with a response rate of $19.4 \%$.

Qualtrics survey software ${ }^{30}$ was used to collect the survey data. Descriptive statistics were used to analyse and present the results of the quantitative data using Microsoft Excel. Data from the open-ended questions were thematically coded in Microsoft Excel using Braun and Clarke's six phases: ${ }^{31}$ 1) familiarising oneself with the data, 2) generating initial codes, 3) searching for themes, 4) reviewing themes, 5) defining and naming themes, and 6) producing the report. Thematic analysis was based on a selection of existing literature and discussions between Author 4 and the primary coder. Author 4 double coded approximately 10 percent of the data to check for interrater reliability. Levels of agreement were high (greater than 90\%) and any inconsistencies were resolved through discussion between the two coders. The CRe-DEPTH guidelines were used to inform the reporting of this evaluation.

\section{Results}

\section{Demographics of MOOC registrants and survey respondents}

Table 1 summarises and compares the demographics of the MOOC registrants and survey respondents revealing that the survey respondents are largely representative of the two cohorts of $\mathrm{MOOC}$ registrants.

Table 1. Comparison of MOOC participants and survey respondents demographic profiles 


\begin{tabular}{|c|c|c|}
\hline & MOOC participants & Survey respondents \\
\hline $\mathrm{N}$ & 3,858 & 748 \\
\hline \multirow[t]{2}{*}{ Gender } & Female: $44 \%$ & Female: $44.1 \%$ \\
\hline & Male: $57 \%$ & Male: $55.9 \%$ \\
\hline Age & Between $20-40$ years: $77.5 \%$ & Between $26-40$ years: $67.5 \%$ \\
\hline \multirow[t]{7}{*}{ WHO Region } & African Region: $62.4 \%$ & African Region: $69.4 \%$ \\
\hline & South-East Asian Region: 17.7\% & \multirow{6}{*}{$\begin{array}{l}\text { South-East Asian Region: } \\
12.6 \% \\
\text { Americas Region: } 9.6 \% \\
\text { Eastern Mediterranean } \\
\text { Region: } 1.6 \% \\
\text { European Region: } 4.1 \% \\
\text { Western Pacific Region: } 2.7 \%\end{array}$} \\
\hline & Americas Region: $9.9 \%$ & \\
\hline & Eastern Mediterranean Region: & \\
\hline & $5.5 \%$ & \\
\hline & European Region: 2.8\% & \\
\hline & 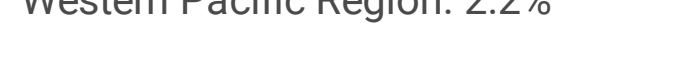 & \\
\hline \multirow[t]{6}{*}{ Profession } & Public health researchers: $45 \%$ & \multirow{2}{*}{$\begin{array}{l}\text { Public health researchers: } \\
31.2 \%\end{array}$} \\
\hline & Public health officers: $15.5 \%$ & \\
\hline & General practitioners: $11.1 \%$ & 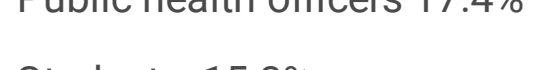 \\
\hline & Students: $11 \%$ & student \\
\hline & & Teachers: $11.4 \%$ \\
\hline & & General practitioners: $9.3 \%$ \\
\hline \multirow[t]{4}{*}{ Education level attained } & Master's degree: $41.5 \%$ & Master's degree: $57.1 \%$ \\
\hline & Bachelor's degree: $24.7 \%$ & Bachelor's degree: $25.6 \%$ \\
\hline & PhD: $10.5 \%$ & \multirow[t]{2}{*}{ PhD/Doctorate: $17.3 \%$} \\
\hline & Medical Doctorate: $17.1 \%$ & \\
\hline \multirow[t]{2}{*}{$\begin{array}{l}\text { Certificate of completion } \\
\text { obtained }\end{array}$} & $\begin{array}{l}\text { Of the total initially enrolled: } \\
30.15 \%\end{array}$ & \multirow[t]{2}{*}{$70.6 \%$} \\
\hline & $\begin{array}{l}\text { Of those who completed the course: } \\
89.2 \%\end{array}$ & \\
\hline
\end{tabular}

\section{Demographics of MOOC registrants}

Of the 3,858 registrants across the May and October MOOC offerings, 1,163 participants $(30.2 \%)$ completed the assessments required to earn a certificate of completion. The MOOC registrants came from 115 different countries with the majority originating from the WHO African Region. The majority of registrants came from English speaking countries (87.2\%) followed by Spanish (7.7\%), French (4.6\%) and Portuguese speaking countries (1.4\%). Figure 1 below shows the regions of origin for the registrants. 
Compared to men, women were more often public health officers ( $51.6 \%$ vs. $46.5 \%)$ and students (56.8\% vs. $43.3 \%)$. Men were more often public health researchers ( $59 \%$ vs. $41 \%)$ and general practitioners ( $57 \%$ vs. $43 \%)$ than women.

\section{Demographics of survey respondents}

The demographic profiles have been combined for the May and October cohorts. The May cohort accounts for $45.4 \%$ of all responses and the October cohort for $54.6 \%$. Of the $748 \mathrm{MOOC}$ participants who took part in the survey, 525 (70.6\%) completed the required assessments to earn a certificate of completion for the MOOC. 11\% indicated that they participated in additional courses on IR following the MOOC. These additional courses included one-day workshops and symposiums, week-long training courses, online courses, one-year certificates, and Master's degree programs. The survey respondents originated from 89 different countries and, as with the $\mathrm{MOOC}$ registrants, the majority of respondents originated from the WHO African Region (69.4\%).

\section{Knowledge of implementation research}

Respondents were asked to indicate their reasons for taking the IR MOOC through a multiple choice question with an 'Other' option. The most commonly cited reasons included 1) To gain knowledge and understanding of IR $(20.8 \%), 2)$ To apply the knowledge and tools in research $(15.1 \%), 3)$ To apply the knowledge and tools in practice $(13 \%), 4)$ For self-learning purposes $(11.3 \%), 5)$ To further specialise in their field (8.5\%), and 6) to obtain a certificate of completion $(7.4 \%)$.

The majority of respondents considered their current knowledge about IR theory (frameworks, models and concepts) to be very good (15.6\%), good (58.4\%), or fair (23.1\%). The IR MOOC contributed to their knowledge to a very large extent (18.1\%), a large extent (50.5\%), or to a moderate extent $(26 \%)$.

In order to understand in further detail which areas respondents felt the IR MOOC had contributed to, they were asked what they considered as the most important insights or experiences gained from the course through an open-ended question. Of the 558 recorded responses to this question, six main themes were identified using Braun and Clarke's six phase analysis. ${ }^{28}$ These themes are as follows:

1. Conceptual understanding of $I R(N=185)$

2. Problem solving aspect of IR $(\mathrm{N}=71)$

3. Applicability or relevance of $I R(N=68)$

4. Research process $(\mathrm{N}=58)$

5. Appreciation of stakeholder and community involvement $(\mathrm{N}=41)$

6. Program evaluation $(\mathrm{N}=36)$

The following sections discuss each of these themes in further detail and provide representative statements. 


\section{Conceptual understanding of implementation research}

The most common theme was that the IR MOOC contributed to respondents' understanding of IR concepts, principles, theories, the importance of IR, and to their understanding why efficacious interventions fail in certain contexts. In relation to the importance of implementing workable solutions, one respondent wrote:

Solutions won't implement themselves. There is work to be done to make sure that the gap between know and do is bridged. (Public health researcher, Nigeria, Obtained certificate)

Another respondent revealed they had learnt the importance of bridging this know-do gap and highlighted that such gaps existed due implementation barriers.

I was able to find out why some programs failed in my State due to lack of data management and inappropriate penetration to the community by the implementers. (Public health officer, Nigeria, Obtained certificate)

Respondents indicated that the knowledge gained included an understanding of why interventions sometimes fail and the importance of including stakeholders in the implementation process to achieve the desired outcomes.

The fact that so many good interventions are always put in place to try to control/prevent NTDs [neglected tropical diseases] from occurring but yet not all were being effective against the particular diseases. This course helped me assess how best certain interventions would be followed to bring about the changes that were highly desired. It also taught me that many stakeholders should be involved in the work you do to achieve the best results. (Uganda, Researcher/microbiologist, Obtained certificate)

Such statements reveal that the MOOC was successful in educating participants about the core concepts of IR.

\section{Problem solving aspect of implementation research}

Respondents identified the importance of IR in identifying methods for solving community health implementation issues in particular contexts. The two representative statements below illustrate this point.

The ability to look at challenges from a broader perspective, visualising the different aspects of the problem and once identified, solutions are easily found. (Cameroon, Public health officer, Obtained certificate)

The most important insights or experiences that I gained from this course were implementation outcomes and implementation strategy. Now I can identify [an] implementation problem and propose a way to resolve it. (Public health researcher, Burkina Faso, Obtained certificate) 
Methods for identifying "bottlenecks" were conveyed throughout the MOOC and respondents appear to have incorporated these learnings into their professional work.

\section{Applicability or relevance of implementation research}

Respondents' comments indicated that they felt the MOOC IR highlighted how IR was applicable or relevant to their profession or research area. One stated:

Stakeholders' involvement at all the stages of implementation research/activities. It was the most important insight because it was very impactful in my professional career. (Public health researcher, Uganda, Obtained certificate)

A second respondent outlined how the knowledge gained though the MOOC will positively impact on their work.

Having participated in community-based intervention programmes in my home country Nigeria, in the past, the knowledge I acquired in the course of the training revealed the causes of most of the challenges encountered and further gave me insight on how to carry out future intervention programmes in such a way that the community benefit more. (Student, China, Obtained certificate)

The applicability of the course material was also relevant to students and teachers as evident from the following statement.

The course helped me to restructure my PhD research work and my teaching materials for my students. (Student/teacher, Nigeria, Obtained certificate)

Respondents could therefore use the knowledge gained from the MOOC to make practical changes in their jobs.

\section{Research process}

In terms of research, respondents found the MOOC helpful in explaining in detail how IR is conducted. This includes designing, planning, and writing IR research proposals, applying for funding, writing publications, and developing research frameworks and methodologies. Representative statements include:

How to write a protocol; How to choose between quantitative/qualitative methods and why/how to use mixed-methods. (Public health researcher, Cameroon, Obtained certificate)

The most important insight gained is how to implement a plan accurately, communicate clear goals and anticipations, and evaluate programs fairly to learn what components are necessary to produce intended effect. (Human resource administrator/Researcher, Nigeria, Obtained certificate)

This finding reveals that respondents felt capable of developing research in IR following the MOOC. 


\section{Appreciation of stakeholder and community involvement}

Respondents stated that the course had contributed to their understanding of the significance of community or stakeholder involvement, engagement or participation in the IR process. Statements include:

I learnt that involving community is vital for the successful implementation of interventions. (Public health researcher, Uganda, Did not obtain certificate)

Involve all the stakeholders from the beginning, make them partners, defining problems and providing solutions with them, improves the effectiveness of research and make it transparent, open and fun! (Research promotion and development administrator, Colombia, Obtained certificate)

As illustrated by the following statement, some respondents displayed a nuanced understanding of how strong community engagement helps maximize the chances that an intervention will succeed.

I understood that community mobilization will assist the community to identify the disease prevalent in the locality and available interventions targeted on diseases and the place they can assess care. This will lead to community involvement and participation, meaning that they will be involved in identifying their felt need. They will also select the trusted village health workers who will be trained to be involved in providing health services to the community. (Public health officer, Nigeria, Obtained certificate)

These findings indicate that the $\mathrm{MOOC}$ was successful in educating participants about the crucial role of stakeholder and community engagement in IR.

\section{Program evaluation}

A final theme relates to the significance of evaluating the effectiveness of implementation of intervention programs. Important learning cited by respondents are highlighted by the three respondents' statements below.

How to use research tools to evaluate and improve on health programs. (Public health officer, Cameroon, Obtained certificate)

The evaluation of existing frameworks in order to introduce interventions that will improve on the status quo. (Student, Ghana, Obtained certificate)

How to assess the appropriateness of existing implementation strategies. (Student, Nigeria, Obtained certificate)

These responses indicate that those surveyed had engaged with the importance of evaluating an intervention's effectiveness.

\section{Changes in professional behaviour}


In relation to changes in respondents' work, the majority stated that the knowledge gained from the course had been valuable to a large extent (43.2\%) followed by valuable to a moderate extent $(27.8 \%)$ and to a very large extent (17.9\%). The majority of respondents have had use for knowledge gained from the MOOC to a very large extent (12.6\%), large extent (36.3\%), or moderate extent (32\%). The majority of respondents have had use for the knowledge gained from the MOOC monthly (30.6\%), rarely (29.9\%), daily $(25.2 \%)$ or weekly $(10.6 \%)$.

Respondents were asked whether they performed their role and responsibilities differently, as a result of participating in the MOOC. $69.1 \%$ agreed, while $30.9 \%$ disagreed. Of the 574 respondents, 330 elaborated on their response. The most common themes cited were:

1. Research processes $(\mathrm{N}=94)$

2. Understanding and thinking about IR and issues related to research $(\mathrm{N}=73)$

3. Stakeholder and community involvement $(\mathrm{N}=46)$

4. Problem solving $(\mathrm{N}=31)$

5. Leadership $(\mathrm{N}=20)$

6. Involvement in IR projects $(\mathrm{N}=18)$

7. Teaching and training others $(\mathrm{N}=16)$

8. Program development, monitoring and evaluation $(\mathrm{N}=13)$

\section{Research processes}

The most commonly cited difference in how respondents performed their role and responsibilities differently as a result of the course related to knowledge of and ability in research processes. This includes designing, planning, identifying research problems, developing research objectives, collecting data, presenting research outcomes, writing research proposals and publications, and applying for research grants. Three illustrative statements of this are presented below.

[The MOOC] helped me in developing a research proposal for my organization, where I used knowledge from this course. (Public health researcher, Nepal, Obtained certificate)

I produced more elaborate reports for projects, and better correspondence as I am able to identify relevant stakeholders. (Public health researcher, Ghana, Obtained certificate)

I have by myself completely written an IR proposal which has been funded. The course gave me the idea to include in my proposal participatory action-research and mixed-methods. I do think this played in my favor and made the proposal accepted by [name of organisation]. (Public health researcher, Cameroon, Obtained certificate)

Respondents' self-reported changes in their research processes and outcomes reveals that the MOOC was successful in teaching IR research approaches. 


\section{Understanding and thinking about implementation research}

The second most commonly found theme included respondents' increased understanding and thinking about IR and both broad and narrow issues related to research. Representative statements include:

These courses have increased my knowledge in the implementation of research and allowed me to have a broad view of things. (Student, Congo, Did not obtain certificate)

From the knowledge gained from MOOC, I have changed how I perceived research implementation. (Internal medicine resident, Rwanda, Obtained certificate)

Such statements reveal the positive impact of the MOOC in shifting and developing participants' thinking and understanding about IR.

\section{Stakeholder and community involvement}

Respondents commonly cited stakeholder and community involvement as an area in which they performed their role and responsibilities differently after participating in the IR MOOC. The following statements illustrate this point.

For all the interventions I plan, I promote the model of district-led-programming $(D L P)$ to allow communities [to] lead the way. (Public health officer, Uganda, Obtained certificate)

I always think of diverse stakeholders necessary for the success of a community-based intervention. (Student, Tanzania, Obtained certificate)

Comments reveal that respondents were aware of the importance of stakeholder and community context, and that including them increases the chances of the success of an intervention:

By following participants of my research to their local areas to learn challenges they face. (Public health researcher, Tanzania, Did not obtain certificate)

I often try to involve stakeholders in public health activities to promote acceptance. (Public health officer, Uganda, Obtained certificate)

The importance of stakeholder and community engagement was cited by respondents in relation to their understanding of IR as well as changes in their professional practice.

\section{Problem solving}

Respondents reported improvements to their ability to solve IR problems as a result of the course, as illustrated by the statements below.

The knowledge gained enables me to find simple yet innovative ways of solving problems. (General practitioner, Ghana, Obtained certificate) 
I have implemented IR in my routine activities with problem solving in mind. (Public health officer, Nigeria, Obtained certificate)

Some respondents described how the knowledge gained from the MOOC had improved their abilities as a researcher and led to positive professional outcomes.

This is because the knowledge I acquired has transformed me into a more ardent researcher with ideas on how to identify and solve implementation problems. These ideas have contributed to designing an implementation research [study] identified by WHO/TDR experts, which gave me a chance of selection as one of the five finalists that attended [name of workshop]. (Public health researcher, Nigeria, Obtained certificate)

As problem-solving is a core component of IR, these statements by respondents reveal that the MOOC successfully communicated this point.

\section{Leadership}

A positive change cited by respondents concerned their increased abilities and roles in leadership. This includes leading research teams, managing research projects, taking on additional responsibilities, and contributing to policy making. Some respondents described the roles they were able to take on as a result of the MOOC.

Provide guidance and knowledge transfer to stakeholders and implementing partners on areas that need to be improved or strengthened in implementation of appropriate interventions, and documentation of the process. (Public health officer, Somalia, Obtained certificate)

One respondent provided an example of how this new ability contributed to their ability to lead research teams nationwide.

As a senior research advisor I am using the skills I have acquired to develop concept notes and protocols for IR and guide research teams across the country. (Public health researcher, Ethiopia, Obtained certificate)

For others, the leadership abilities assisted them to improve the implementation of public health programming.

As a programme manager, it has helped me guide programme implementation in identifying gaps and steps/required interventions to achieve desired implementation outcomes. (Public health officer, Nigeria, Obtained certificate)

\section{Involvement in implementation research projects}

Respondents identified increased involvement in a range of IR projects as a result of the MOOC. This is illustrated by the following statements. 
I have conducted TB implementation research in my country. (Research and development/Private sector, Sudan, Obtained certificate)

I have been part of various teams in Nigeria developing and working on implementation research. (Public health officer, Nigeria Did not obtain certificate)

Some respondents described how the $\mathrm{MOOC}$ had refreshed their knowledge and enabled them to apply it to IR projects.

My MPH training included some coursework on implementation science (IS) but the MOOC really helped me refresh my knowledge and apply IS lens to my role at [organisation name]. My role is focused on managing global health security project implementation across several countries in Africa and Asia. (Public health officer, US, Obtained certificate)

\section{Teaching and training others}

Respondents indicated that the course had assisted them in their roles and responsibilities regarding teaching and training.

As a programme manager, it has helped me guide programme implementation in identifying gaps and steps/required interventions to achieve desired implementation outcomes. (Public health officer, Nigeria, Obtained certificate)

Some participants stated that the course had improved their thinking around teaching and training.

I now design and teach research in a manner that its findings could be implemented. (Teacher, Nigeria, Obtained certificate)

Greater clarity when advising students how to execute their investigations in the field of tuberculosis in the Master of Epidemiology at [university name]. (translated from Spanish) (Teacher, Colombia, Obtained certificate)

Others indicated that the MOOC had increased their confidence in this area.

I feel more confident to train others in IR. (Public health researcher, Colombia, Obtained certificate)

\section{Program development, monitoring and evaluation}

The MOOC increased respondents' skills within general program development, monitoring and evaluation.

I ensure that the interventions targeted at the diseases of poverty are utilized by the communities. (Public health officer, Nigeria, Obtained certificate)

I have been able to assess bottlenecks from a systems point of view and realize how these bottlenecks can or could be solved with implementation research which helps us to understand why they are 
occurring in the first place. (Student, Malawi, Obtained certificate)

Some respondents indicated they were able to transfer this knowledge to other areas.

After taking the course, I used knowledge gained in assessing the Adolescent Sexual and Reproductive Health program running in my district and I used findings to change some methods in adolescents education and care in school and at health facilities in my district. (Public health officer, Ghana, Obtained certificate)

A second participant stated:

In that I turn every public health program (food safety programs for instance) around to detect any possible gap in its implementation and find solutions to them before getting it out to its consumers or beneficiaries. (Regulatory officer, Ghana, Obtained certificate)

Such findings are important in that they confirm the usefulness of the IR MOOC in developing participants' ability to develop, monitor and evaluate programs that are not focused on infectious diseases of poverty.

\section{Discussion}

The IR MOOC sessions offered in 2018 reached the targeted audience, namely those working within public health and research in LMICs. Those surveyed were largely representative of the participants of the two sessions of the 2018 IR MOOC. Most registrants and survey respondents were located in Africa and South-East Asia where implementation challenges are often the greatest. The IR MOOC participants and survey respondents mainly worked as public health researchers or public health officers and the range of individuals was broad in regard to country, profession, level of education, gender and age. These characteristics suggest that the IR MOOC was able to reach people from a variety of contexts and backgrounds who were in need of training. This is particularly relevant to IR in LMICs where health systems are often underdeveloped and there is a lack of established approaches to collecting and using locally generated information. ${ }^{2}$ In these contexts, researchers are needed to create locally relevant evidence-based solutions to implementation challenges in order to ensure that interventions are relevant, sustainable, and optimally delivered in order to reach the intended audience at scale.

The IR MOOC was successful in its aim of strengthening participants' knowledge of IR. The majority of respondents considered their current knowledge IR to be very good $(15.6 \%)$ or good $(58.4 \%)$ and that the IR MOOC contributed to their knowledge to a very large extent (18.1\%) or a large extent $(50.5 \%)$. In relation to specific areas of knowledge gained from the course, the thematic analysis responses revealed that a conceptual understanding of IR was the most commonly cited point of learning. This included an understanding of IR concepts, principles, theories, the importance of IR, and understanding why efficacious interventions fail in certain contexts. Following this, IR problem-solving, including the identification of bottlenecks, and the applicability or relevance of IR, were the next most cited themes. 
Respondents stated that they had learnt about the importance of including stakeholders and communities throughout the IR process in order to achieve the best possible outcomes. These findings indicate that the MOOC was an effective means of educating people in IR concepts; participants reported that the MOOC contributed to their learning and they were able to retain the content for future professional use. Such insights are crucial to building research capacity to identify, develop and implement interventions that are able to overcome challenges that may hinder successful outcomes. This is particularly the case in LMICs and in relation to combating infectious diseases of poverty and the growing burden of non-communicable diseases. ${ }^{32}$

The IR MOOC proved successful in strengthening participants' professional practice in relation to IR as participants were able to apply the MOOC content in their daily professional lives. In terms of changes in respondents' daily professional behaviour as a result of the IR MOOC, respondents report using the new knowledge and skills that they gained from the course fairly frequently and that these are of professional value. These findings are similar to those of an evaluation of a $\mathrm{MOOC}$ on implementation science using Kirkpatrick's Model ${ }^{4}$ which likewise revealed positive short- and long-term learning outcomes; Participants indicated that they found the different theories, models and frameworks applicable to their own research and appreciated the research networks that they gained access to. In the current study, the most commonly cited themes in regard to changes to respondents' roles and responsibilities include changes to how they approach the research process, their understanding and thinking about IR and IR research. Respondents reported improvements in how they approach problem solving, including identifying bottlenecks, and how they approach stakeholder and community engagement with IR activities. For many, the MOOC had increased opportunities for or in for leadership roles, as well as involvement in IR projects. A further positive finding was that respondents were able to transfer their learning from the IR $\mathrm{MOOC}$ to develop, monitor and evaluate programs that deal with health issues that do not specifically target infectious diseases of poverty.

While the overwhelming majority of respondents' comments were positive, not all were. Several respondents stated that they were unable to complete the $\mathrm{MOOC}$ due to heavy workloads or poor internet connections. Not all respondents were able to apply the knowledge and skills to a large extent, and many stated that they had faced barriers to implementing the knowledge and skills that they learnt in the course in the workplace. This is explored further in a separate article focusing on the participants' self-reported use of the knowledge gained in the $\mathrm{MOOC}$ in their professional work and the barriers encountered in the workplace. ${ }^{33}$

These findings provide positive evidence that MOOCs can be used as a tool to further knowledge of, and engagement in IR. This is particularly important given many of the available evidence-based interventions do not have significant impacts when introduced at scale. ${ }^{1}$ Bottlenecks and a lack of local stakeholder and community engagement are a particular issue to implementing efficacious health interventions in LMICs, where health systems may be underdeveloped and lack established mechanisms to employ 
locally generated information. ${ }^{2}$ Respondents of the IR MOOC felt that these were areas in which they had gained important knowledge and that they were able to apply this in their professional practice.

\section{Conclusion}

The IR MOOC was successful in targeting people from a variety of LMIC contexts and backgrounds and in strengthening their knowledge of IR. Furthermore, learners of the MOOC were able to apply this knowledge of IR in their professional practice. As such, MOOCs can be seen as a proven method of delivering IR education to LMIC learners who may not have access to formal learning pathways such as university courses. This is particularly relevant to learners in LMICs, where challenges in relation to implementation are often encountered.. Furthermore, MOOCs can also be utilized to satisfy the increasing interest in, and growing demand for IR training within the general population.

\section{Study Limitations}

A number of limitations are worth noting for this study. First, response bias may contribute to the positive results reported here, as there may be differences between those who responded to the survey request versus those who do not. ${ }^{34}$ Survey and interview respondents are highly self-selective and this may be linked to learners with autonomous motivations for behaviour. ${ }^{35-36}$ The data is self-reported by participants and may therefore present validity issues. The lack of a control group is a further limitation to the study.

\section{Abbreviations}

IR

implementation research

LMICs

low- and middle-income countries

MOOC

massive open online course

TDR

Special Programme for Research and Training in Tropical Diseases

WHO

World Health Organisation

\section{Declarations}

Acknowledgements

Not applicable

Ethics approval and consent to participate

Page $17 / 23$ 
The need for ethics approval and consent was waived.

\section{Consent for publication}

Not applicable

\section{Availability of data and material}

The datasets analysed during the current study are available from the corresponding author on reasonable request.

\section{Competing interests}

BR and MJP declare that they have no competing interests. PL, DM and EC work for TDR, which funded the development of the MOOC.

\section{Funding}

TDR funded the development of the MOOC.

\section{Authors' contributions}

PL and DM conceived of the paper. BR drafted the initial form with assistance from MJP. PL, DM, EC, BR and $\mathrm{MJ}$ all made significant contributions to the conceptual framework and read and modified drafts. All authors ( $\mathrm{PL}, \mathrm{DM}, \mathrm{EC}, \mathrm{BR}$ and $\mathrm{MJ}$ ) read and approved the final manuscript.

\section{References}

1. Madon T, Hofman KJ, Kupfer L, Glass RI. Implementation Science. 2007; 318 (5857): 1728-1729. doi: 10.1126/science. 1150009

2. Sheikh K, Agyepong I, Jhalani M, Ammar W, Hafeez A. Pyakuryal S, et al. Learning health systems: An empowering agenda for low-income and middle-income countries. Lancet. 2000;395(10223):476.

3. Brownson RC, Colditz GA, Proctor EK. Dissemination and implementation research in health: Translating science to practice. Oxford University Press. 2008

4. Carlfjord S, Roback K, Nilsen P. Five years' experience of an annual course on implementation science: an evaluation among course participants. Implementation Science. 2017;12(1):101.

5. Chambers DA, Proctor EK, Brownson RC, Straus SE. Mapping training needs for dissemination and implementation research: lessons from a synthesis of existing DI research training programs. Translational Behavioral Medicine, 7(3), 593-601. 2017. doi:10.1007/s13142-016-0399-3

6. World Health Organization. Implementation research platform. 2019. Available from: https://www.who.int/alliance-hpsr/implementationresearchplatform/en/. Accessed 7 Oct 2019. 
7. Launois P, Allotey P, Reidpath D, Maher D, Certain E, Ross B. Lessons learnt from a professional development MOOC: Engaging culturally and linguistically diverse learners from low- and middleincome countries. European Journal of Open, Distance and E-Learning. 2019. https://doi.org/http://www.eurodl.org/?p=current\&sp=brief\&article=809

8. Salmon G, Gregory J, Lokuge Dona K, Ross B. Experiential online development for educators: The example of the Carpe Diem MOOC. British Journal of Educational Technology. 2015;46(3):542-556. doi:10.1111/bjet.12256

9. Hossain MS, Islam MS, Glinsky JV, Lowe R, Lowe T, Harvey LA. A massive open online course (MOOC) can be used to teach physiotherapy students about spinal cord injuries: a randomised trial. Journal of Physiotherapy. 2015; 61(1):21-27. doi:10.1016/j.jphys.2014.09.008

10. George PP, Papachristou N, Belisario JM, Wang W, Wark PA, Cotic Z, et al. Online eLearning for undergraduates in health professions: a systematic review of the impact on knowledge, skills, attitudes and satisfaction. Journal of Global Health. 2014;4(1). doi:10.7189/jogh.04.01040

11. Breslow L, Pritchard DE, DeBoer J, Stump GS, Ho AD, Seaton DT. Studying learning in the worldwide classroom: Research into edX's first MOOC. Research Practice in Assessment. 2013;8:13-25. doi:10.19173/irrodl.v18i5.3080

12. Hew KF, Cheung WS. Students' and instructors' use of massive open online courses (MOOCs): Motivations and challenges. Educational Research Review. 2014;12:45-58. doi:10.1016/j.edurev.2014.05.001

13. Zhenghao C, Alcorn B, Christensen G., Eriksson N, Koller D, Emanuel E. Who's Benefiting from MOOCs, and Why. Harvard Business Review [Blog post]. 2015 Sep 22. https://hbr.org/2015/09/whosbenefiting-from-moocs-and-why

14. Garrido M, Koepke L, Andersen S, Mena A, Macapagal M, Dalvit L. An examination of MOOC usage for professional workforce development outcomes in Colombia, the Philippines South Africa. Seattle: Technology Social Change Group; 2016 Apr 8.

15. Hrdličková Z, Dooley G. AuthorAID capacity development impact study. 2017 (Summary Report). Available from: https://www.inasp.info/AuthorAIDstudy

16. Murugesan R, Nobes A, Wild J. A MOOC approach for training researchers in developing countries. Open Praxis. 2007;9(1):45-57. doi:10.5944/openpraxis.9.1.476

17. Blume BD, Ford JK, Baldwin TT, Huang JL. Transfer of training: A meta-analytic review. Journal of Management. 2010;36(4):1065-1105.

18. Grossman R, Salas E. The transfer of training: what really matters. International Journal of Training and Development. 2011;15(2):103-120. doi: 1111/j.1468-2419.2011.00373.x

19. Reeder JC, Guth, JA. What have we learned from 40 years of supporting research and capacity building? PLoS Neglected Tropical Diseases. 2015; 9(1), doi:10.1371/journal.pntd.0003355

20. Implementation research training materials. 2018. Available from: https://www.who.int/tdr/capacity/strengthening/ir-training/en/ 
21. Hooley C, Baumann A, Mutabazi V, Brown A, Re D, Cade WT, et al. (Under review). The TDR MOOC training in implementation research: Evaluation and lessons learned in Rwanda. Submitted to Implementation Science.

22. Chapman SA, Goodman S, Jawitz J, Deacon A. A strategy for monitoring and evaluating massive open online courses. Evaluation and Program Planning. 2016; 57:55-63.

23. Ayub E, Wei GW, Yue WS. Exploring factors affecting learners' acceptance of MOOCs based on Kirkpatrick's Model. In: Proceedings of the 8th International Conference on E-Education, E-Business, E-Management and E-Learning. New York, NY, USA: ACM. 2017;16:34-9.

24. Goh WW, Wong SY, Ayub E. The effectiveness of MOOC among learners based on Kirkpatrick's model. Redesigning Learning for Greater Social Impact. 2018;313-23.

25. Lin J, Cantoni L. Assessing the performance of a tourism MOOC using the Kirkpatrick model: a supplier's point of view. Information and Communication Technologies in Tourism. 2017: 15:129-42.

26. Meinert E, Alturkistani A, Car J, Carter A, Wells G, Brindley D. Real-world evidence for postgraduate students and professionals in healthcare: Protocol for the design of a blended massive open online course. BMJ Open. 2018; 8(9), e025196.

27. Meinert E, Alturkistani A, Brindley D, Carter A, Wells G, Car J. Protocol for a mixed-methods evaluation of a massive open online course on real world evidence. BMJ Open. 2018; 8(8), e025188.

28. Kirkpatrick D, Kirkpatrick J. Evaluating training programs: The four levels. Berrett-Koehler Publishers. 2006.

29. Nwameme A, Dako-Gyeke P, Asampong E, Allotey P, Reidpath DD, Certain E, et al. (in prep.). Does the TDR MOOC on Implementation Research (IR) with a focus on IDPs improve the understanding of IR in participants from LMICs?

30. Qualtrics, Provo, UT, USA. https://www.qualtrics.com

31. Braun V, Clarke V. Using thematic analysis in psychology. Qualitative Research in Psychology. 2006;3(2):77-101.

32. Piot P, Caldwell A, Lamptey P, Nyrirenda M, Mehra S, Cahill K, Aerts A. Addressing the growing burden of non-communicable disease by leveraging lessons from infectious disease management. Journal of global health. 2006;6(1). doi: 10.7189/jogh.06.010304

33. Launois P, Maher D, Certain E, Ross B, Penkunas MJ (in prep) The Implementation Research MOOC: Evaluating results using Kirkpatrick's Four-Level Model.

34. Peytchev A, Baxter RK, Carley-Baxter, L R. Not all survey effort is equal: Reduction of nonresponse bias and nonresponse error. Public Opinion Quarterly. 2009; 73(4):785-

35. Deci EL, Ryan RM. Intrinsic motivation and self-determination in human behavior. New York: Plenum. 1985.

36. Ryan RM, Deci EL. Self-determination theory and the facilitation of intrinsic motivation, social development, and well-being. American psychologist. 2000; 55(1):68. 


\section{Figures}

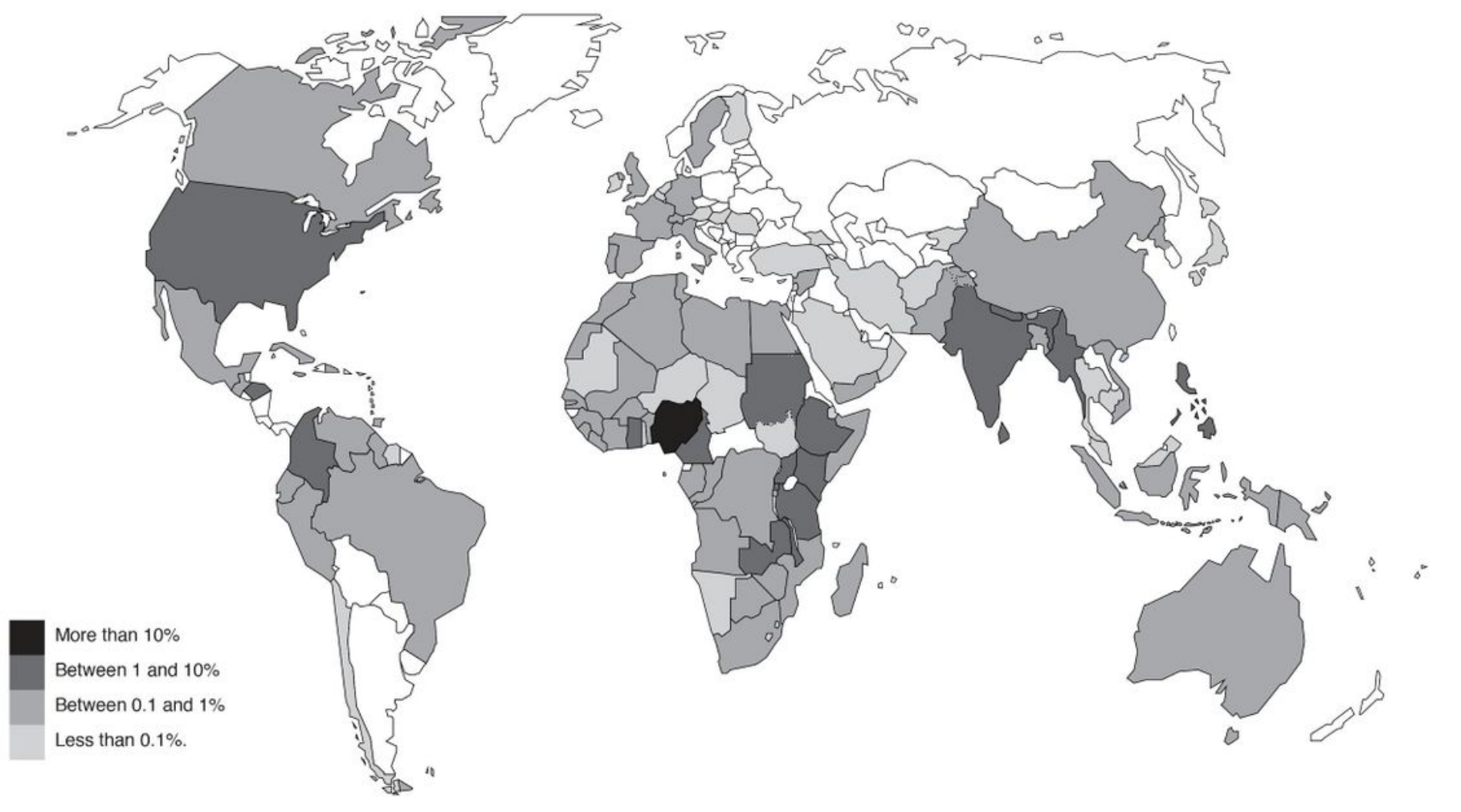

World Health The boundaries and names shown and the designations used on this map do not imply the expression of any opinion Organization of its authorities, or concerning the delimitation of its frontiers or boundaries. Dotted and dashed lines on maps represent

\section{Figure 1}

Represented countries of $\mathrm{MOOC}$ registrants Note: The designations employed and the presentation of the material on this map do not imply the expression of any opinion whatsoever on the part of Research Square concerning the legal status of any country, territory, city or area or of its authorities, or concerning the delimitation of its frontiers or boundaries. This map has been provided by the authors. 


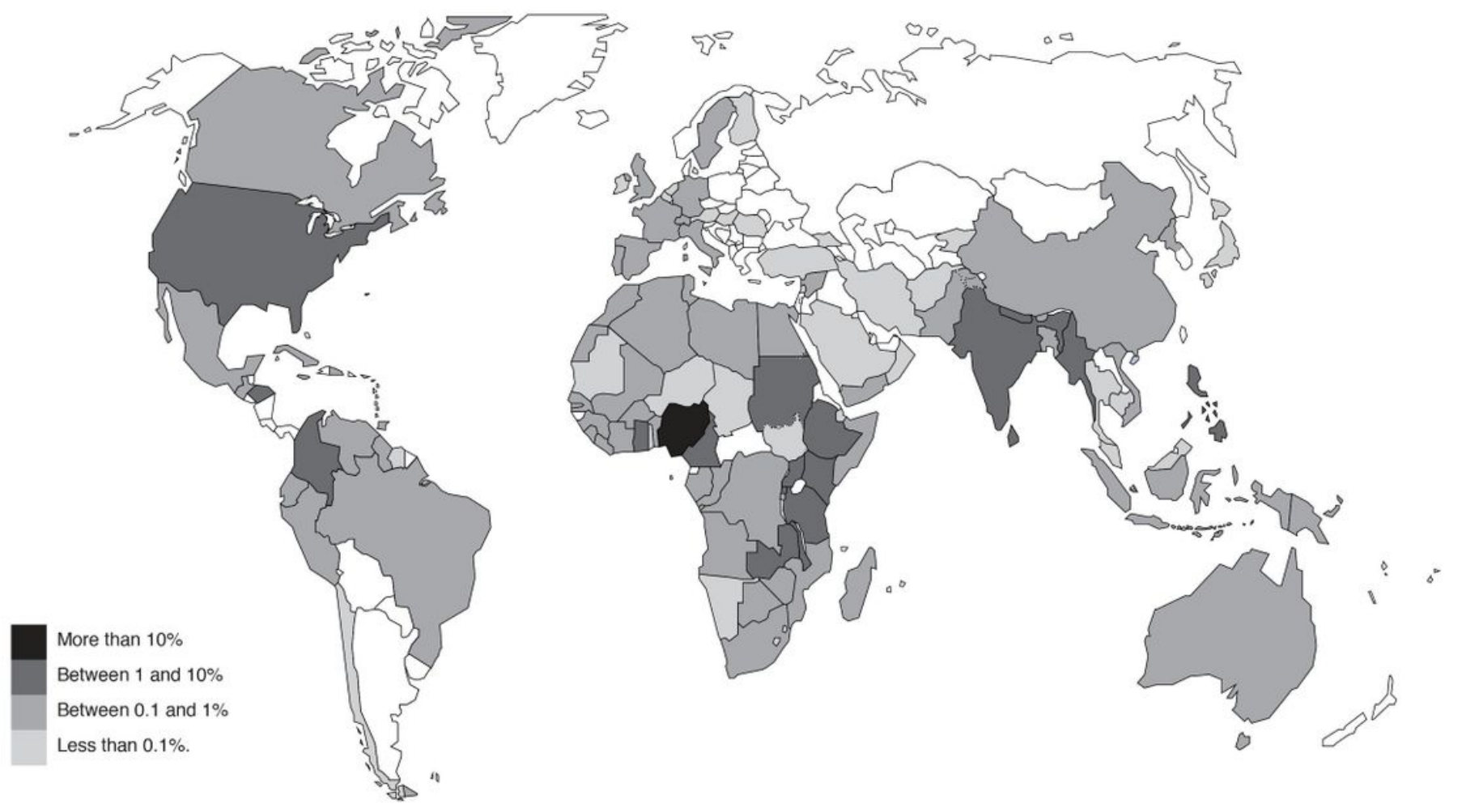

World Health The boundaries and names shown and the designations used on this map do not imply the expression of any opinion

Organization of its authorities, or concerning the delimitation of its frontiers or boundaries. Dotted and dashed lines on maps represent
approximate border lines for which there may not yet be full agreement. 0 WHO 2012. All rights reserved.

Data Source: World Health Organization Map Production: WHO Graphics

\section{Figure 1}

Represented countries of $\mathrm{MOOC}$ registrants Note: The designations employed and the presentation of the material on this map do not imply the expression of any opinion whatsoever on the part of Research Square concerning the legal status of any country, territory, city or area or of its authorities, or concerning the delimitation of its frontiers or boundaries. This map has been provided by the authors. 


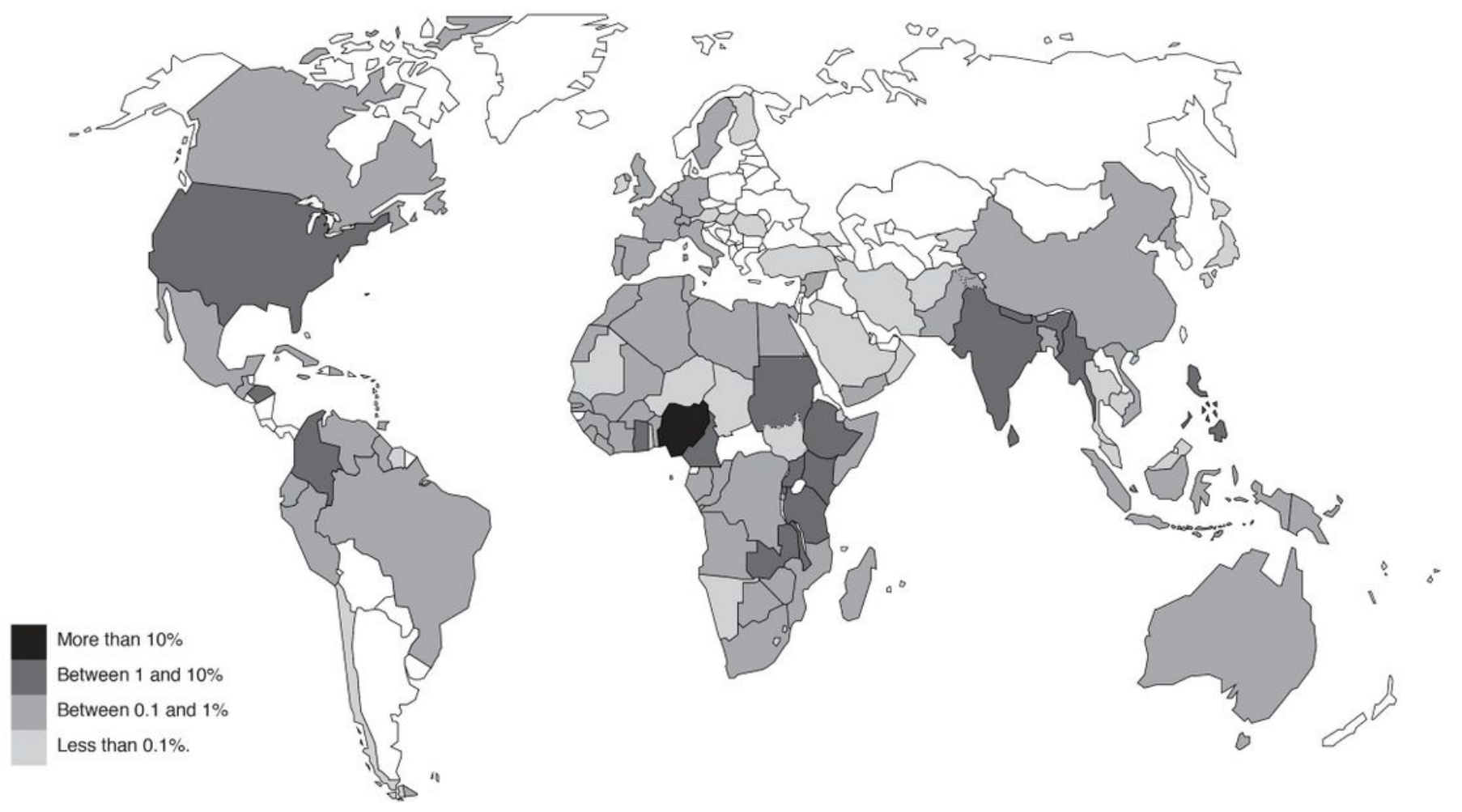

World Health The boundaries and names shown and the designations used on this map do not imply the expression of any opinion Organization of its authorities, or concerning the delimitation of its frontiers or boundaries. Dotted and dashed lines on maps represent
approximate border lines for which there may not yet be full agreement. O WHO 2012. All rights reserved.

Data Source: World Health Organization

Map Production: WHO Graphics

\section{Figure 1}

Represented countries of $\mathrm{MOOC}$ registrants Note: The designations employed and the presentation of the material on this map do not imply the expression of any opinion whatsoever on the part of Research Square concerning the legal status of any country, territory, city or area or of its authorities, or concerning the delimitation of its frontiers or boundaries. This map has been provided by the authors.

\section{Supplementary Files}

This is a list of supplementary files associated with this preprint. Click to download.

- CReDEPTHchecklistMOOCEvaluation.docx

- CReDEPTHchecklistMOOCEvaluation.docx

- CReDEPTHchecklistMOOCEvaluation.docx 